\title{
External post-tensioning system for the strengthening of historical stone masonry bridges.
}

\author{
Alejandro Jiménez Rios', Dermot O’Dwyer²
}

\begin{abstract}
Most historical stone masonry bridges were designed and built several centuries ago based in loads comparatively lower than the ones to which those structures are subjected to nowadays. Because of this fact and the normal decay and damage presented by historical structures, the need of strengthening arises and gives place to proposals such as the one presented in this paper.
\end{abstract}

The objective of this paper is to present the evaluation of the feasibility of the use of an external post-tensioning arrangement to strengthen historical stone masonry bridges. The arrangement proposed is an alternative to those already existent and developed by other authors.

To verify the assumed hypothesis, the proposal was analyzed with a general-purpose finite element method software, ANSYS. A qualitative assessment of this and other strengthening techniques available and used nowadays is also presented to evaluate its application suitability to historical structures.

The results obtained via simple non-linear FEM models show that the proposal effectively increases the ultimate load capacity of the arch ring. It is also shown that the external post-tensioning arrangement can contain at certain level the horizontal thrust at the abutments. The proposed technique is deemed to be sympathetic and has great potential to be used to repair, strengthen and retrofit historical stone masonry bridges.

Keywords: historical stone masonry bridges, post-tensioning, strengthening, non-linear FEM, ANSYS.

\section{Introduction}

The field of strengthening and retrofitting of masonry arch bridges is of great importance since nowadays, only in Ireland, up to 20000 such structures exist and are part of the rail, road and waterway Irish national network [1]. Interventions of this kind must be implemented attending the recommendations and principles stablished in multiple international conservation charters and in a sympathetic manner. From another perspective, this proposal is justified by the fact that most masonry arch bridges were designed and built several centuries ago. Such designs were usually based in loads comparatively lower than the ones to which those structures are subjected to nowadays.

\footnotetext{
${ }^{1} \mathrm{PhD}$ Student, Department of Civil, Structural and Environmental Engineering, Trinity College Dublin - TCD, Dublin, Ireland, jimnezra@tcd.ie

${ }^{2}$ Associate Professor, Department of Civil, Structural and Environmental Engineering, Trinity College Dublin - TCD, Dublin, Ireland, dwodwyer@tcd.ie
} 
The arrangement proposed is an alternative to those already existent and developed by other authors (see [2] and [3]). The main hypotheses behind this proposal are based in simple and already proven concepts on the structural behavior of masonry arches [4]. The proposed strengthening technique was developed with the following purposes in mind:

- To improve the stability of the arch and its ultimate load capacity.

- To contain part of the horizontal thrust at the abutments.

- To increase the symmetric loads in the bridge, therefore reducing the negative effect of non-symmetrical loads.

The paper consists then in a brief description of the state of the art of the field. Then the different models and results of the multiple analyses carried out to assess a simple stone masonry arch ring are presented. Pros and cons of the different intervention techniques used nowadays and the new proposal are discussed briefly. Conclusions are finally presented at the end of the paper.

\section{State of the art}

Several post-tensioning strengthening techniques have been developed and applied by other authors to increase the ultimate load capacity of masonry arches. Even though they use different devices and configurations, all of them have the same goal: to ensure the stability of the structure by increasing the compressive stresses within the arch.

\subsection{RAM (Reinforced Arch Method)}

One of those techniques which has proved to be very efficient was developed by Jurina [2]. He proposed the installation of a cable all along the length of the arch, either at extrados or intrados level, anchored at the abutments of the arch. The cable is post-tensioned and achieves to induce compressive stresses all along the arch, which in fact can close existent cracks and increase the stability of the structure. His proposal, has been validated with experiments and numerical simulations. It has been applied in several structures along Italy. The schematics of this system are shown in Fig. 1.

\subsection{Borri and Castori's system}

Another post-tensioning technique has been developed by Borri and Castori [3]. It uses an arrangement of steel reinforced grout strips attached to the extrados of the arch that induce compressive stresses all along the span, thus increasing its stability and ultimate load capacity. According to the authors, the system applied uses the most up-to-date techniques and technologies at the service of culture, respect the historic value of the ancient buildings and provides an adequate safety level whilst changing as little as possible the original structural conception. Borri and Castori's system has already been used to retrofit several buildings also in Italy. It is shown in Fig. 2. 


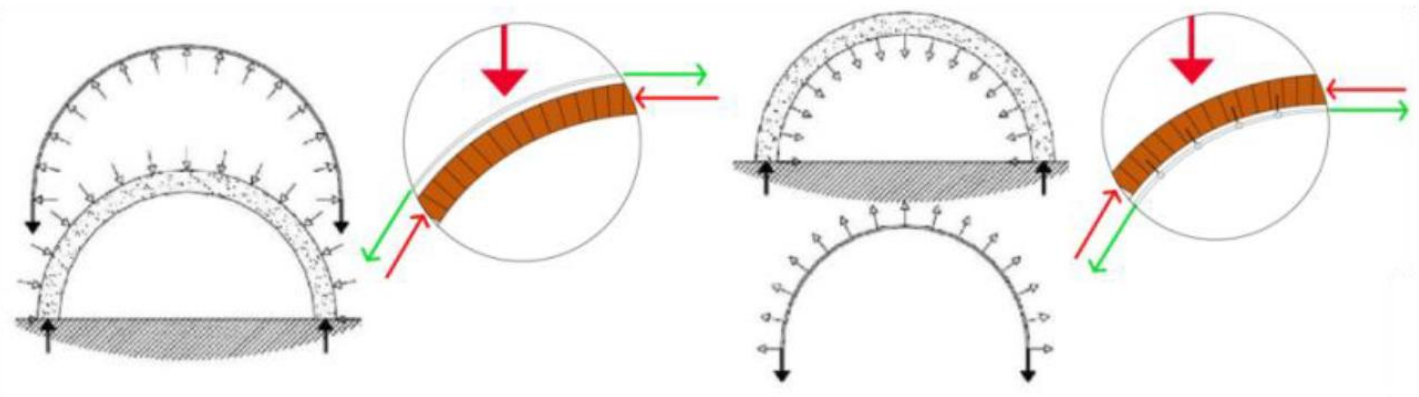

Figure 1. Jurina's "RAM" system schematics [2].

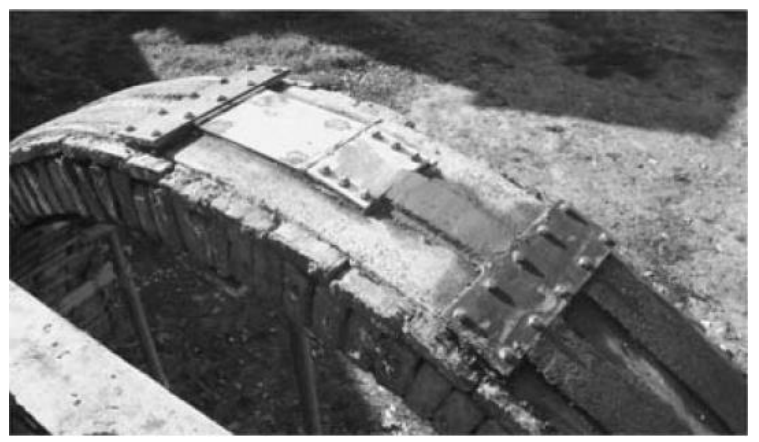

Figure 2. Arch after intervention using Borri and Castori's system [3].

\section{Modelling and strengthening proposal assessment}

\subsection{Geometry and material properties}

An idealized semicircle single span stone masonry arch bridge was analyzed. The set-up of the model and the geometry are shown in Fig. 3. The material used is granite and its properties are presented in Table 1. These properties were obtained from averaged values presented in two different sources (see [5] and [6]).

2-D plane stress analysis, assuming a value of $1 \mathrm{~m}$ for the depth of the vousoirs, was performed. Rough nonlinear contacts were modelled with the aim of reproducing the assumptions of non-sliding between blocks and zero tensile strength for the masonry considered by the plasticity limit analysis theory [7]. Large deformations were also considered and a numerical iterative solver was used to find the ultimate load capacity of the arch. All simulations were performed using ANSYS [8].

\subsection{Strengthening proposal}

The proposal developed and presented in this paper consists in an external arrangement of post-tensioned cables anchored to the arch ring stones and to a central anchoring device. Its external nature allows the pre-stress force to be implemented in an incremental way and to be modified in case it is required. It can be classified as an active strengthening technique.

It aims to increase the compressive stresses in the arch, therefore improving its stability and consequently, increasing its ultimate load capacity. Three different cable arrangements were studied. Sketches of the arrangements as well as of the anchoring device can be seen in Fig. 4. After some preliminary simulations, it was 
noticed that the 3 cables arrangement could prompt the formation of 2 hinges at the quarter's span length and therefore accelerate the formation of the full collapse mechanism of the arch. Therefore, arrangements for 4 and 5 cables at each location of the formation of the hinges of the full collapse mechanism, for asymmetric and symmetric load respectively, were studied as an alternative and in more detail.

Table 1. Granite properties used for the FEM analysis.

\begin{tabular}{|c|c|}
\hline Stone type & Granite \\
\hline Compressive strength $(\mathrm{Pa})$ & $1 \times 10^{8}$ \\
\hline Specific weight $\left(\mathrm{kg} / \mathrm{m}^{3}\right)$ & 2500 \\
\hline Young Modulus $(\mathrm{Pa})$ & $5 \times 10^{10}$ \\
\hline Poisson's Ratio & 0.3 \\
\hline
\end{tabular}

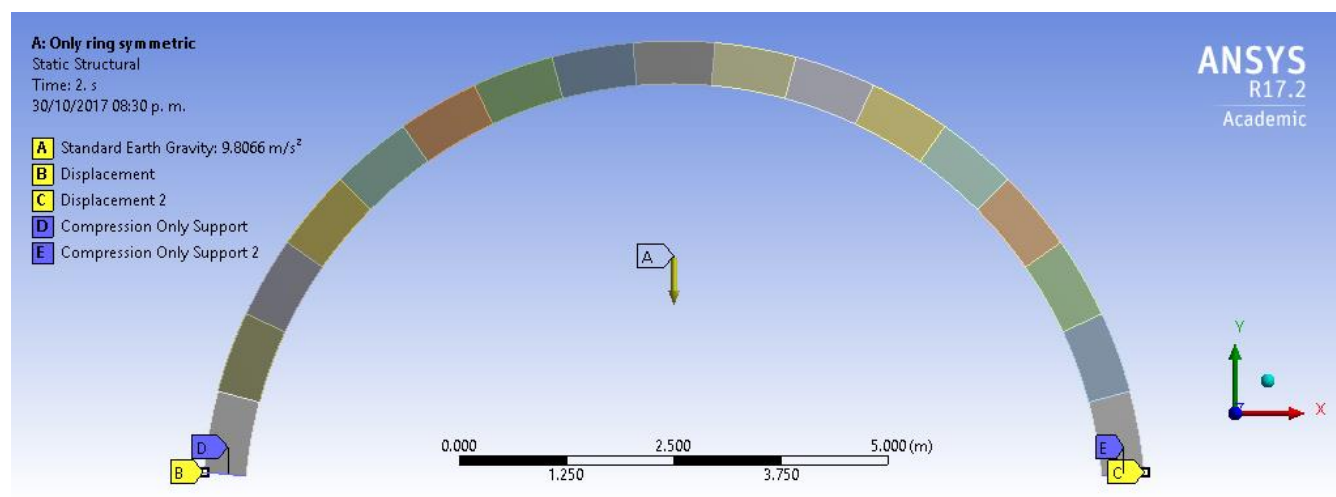

Figure 3. FEM 2-D plane stress linear elastic analysis set-up.

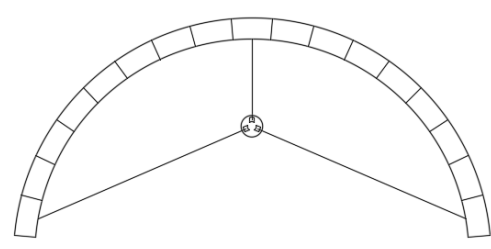

(a)

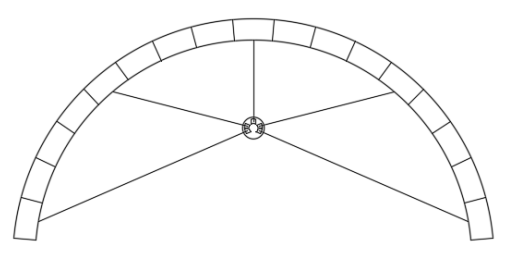

(c)

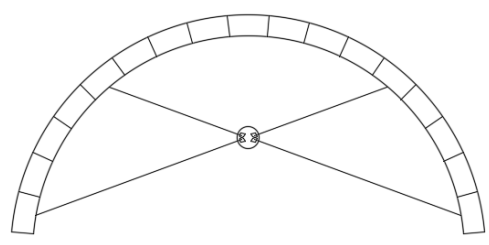

(b)

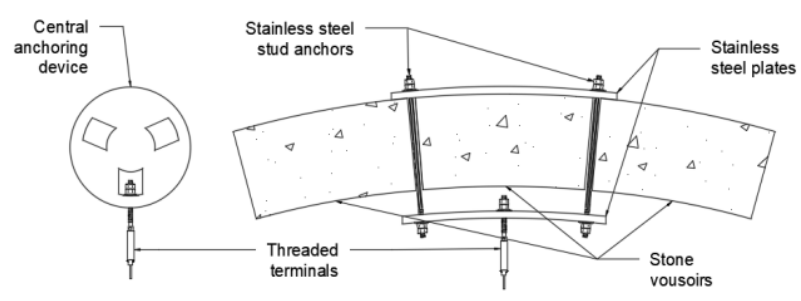

(d)

Figure 4. Cable arrangements: (a) 3 cables arrangement, (b) 4 cables arrangement, (c) 5 cables arrangement, (d) Central anchoring device for 3 cables arrangement $\&$ anchoring at stone vousoir (sketches without scale).

\section{Results and discussion}

\subsection{Non-reinforced model}

Two steps were used to run the numerical model. In the first step only earth gravity was applied and in the last one the external point load was added. This was done with the aim of observing the structural behavior of the 
arch under different load scenarios. Convergence of the solution was achieved for an ultimate load capacity value of $4.2 \mathrm{kN}$.

In Fig. 5 the vertical displacements are shown. At the center of the arch, which is where the point load is applied, the displacements are negative, but on the other hand, the displacements at the quarters of the span are positive, which indicates lifting in those locations. It is also important to notice the formation of the collapse mechanism and that since the load application is symmetrical, it develops 5 hinges, one at each support, one in the center of the arch and one at each of the quarter's spans of the arch as well.

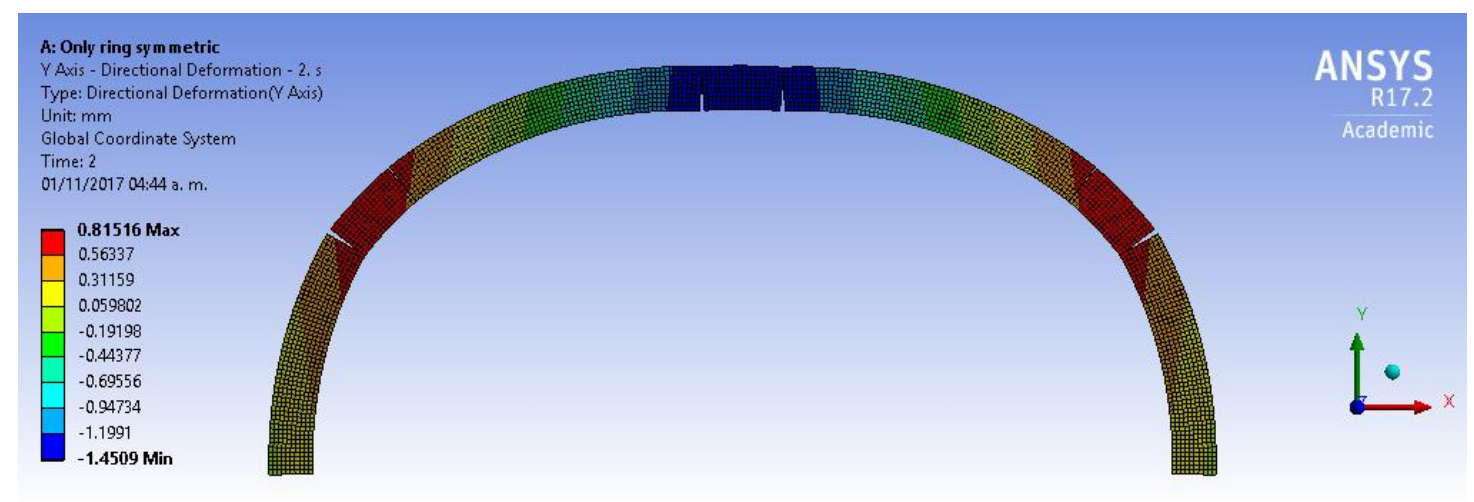

Figure 5. Vertical displacements.

Finally, Fig. 6 shows the pressure developed at the contact points between stone vousoirs. The maximum pressure has a value of only 3.14 $\mathrm{MPa}$, which is relatively small in comparison with the compressive strength of the granite, in this case assumed to be of $100 \mathrm{MPa}$. This justifies the last of the assumptions stablished by the plasticity theory regarding the infinite compressive strength of the masonry [7]. From the point of view of the FEM, the use of a linear behavior of the material can be justified since the stresses developed in the stone are less than $10 \%$ of its compressive strength, therefore assuring that the material stays within its elastic behavior range and no crushing or cracking is developed within the vousoirs.

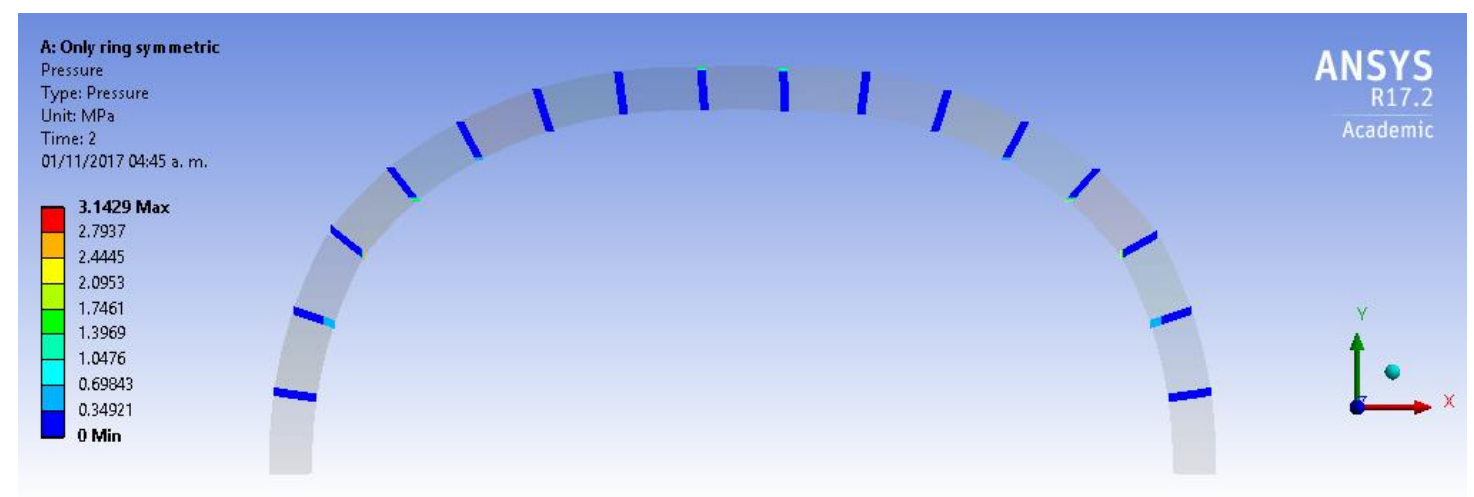

Figure 6. Contacts pressures.

\subsection{Reinforced model}

The model used to assess the effect of the external post-tensioning forces on the arch ring uses an assumption that allowed to simplify the analysis. It consists in the indirect modelling of the cables. In this model only the 
forces of the cables are modelled, not the cables themselves. It is well known that in any post-tensioning process losses occur due to several factors and the deformations in the element. To better assess those effects, further and more advanced simulation will be required. Since this report's scope is limited to a first approach, those results are not included.

The loads were applied in 3 different steps. The self-weight of the structure was applied in the first step. In the second one, the post-tensioning forces were added and finally, the external point load at the center of the arch ring was applied in the last time step. This was useful to identify the effect of the mentioned loads separately and its influence in the structure's behavior.

Since the 4 cables arrangement was the most efficient one of the studied arrangements and the most critical load condition was the symmetric one, only the results for that simulation set-up are presented. The set-up of the model is shown in Fig. 7. Ten different levels of post-tensioning were modelled to better understand its influence in the performance of the structure. Those values are presented in Table 2 along with the correspondent values of the ultimate load, maximum contact pressures, and horizontal thrust reduction at abutments. It should be noticed that the values for the post-tensioning force given in Table 2 correspond to the value of the forces at each one of the cables thus, equilibrium is achieved at the center of the anchoring device.

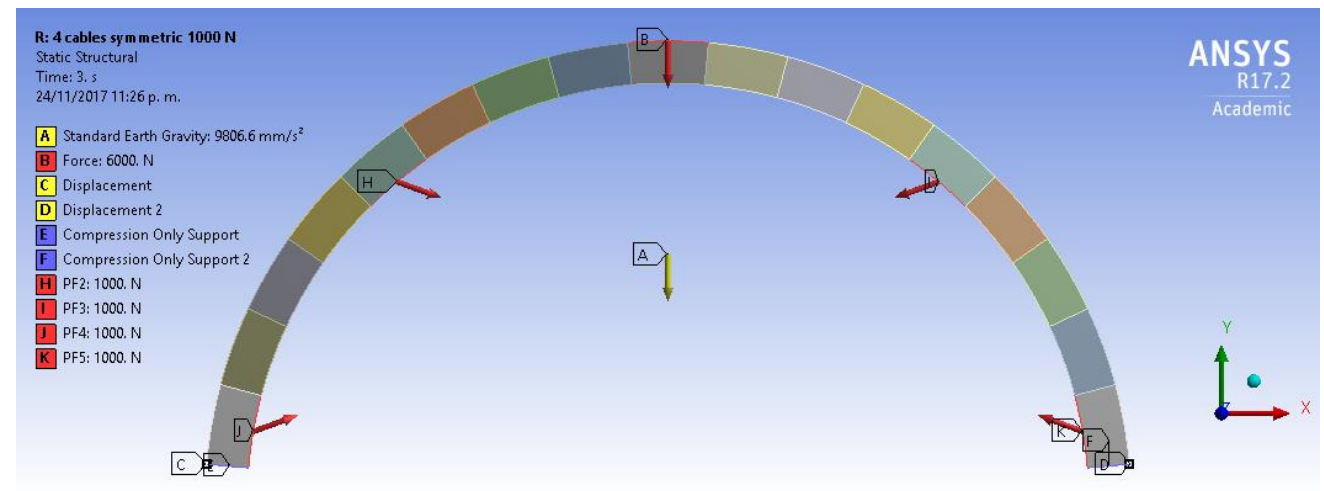

Figure 7. Set-up of the FEM non-linear model including the post-tensioning forces.

Table 2. Ultimate load capacities of the arch ring after several levels of post-tensioning.

\begin{tabular}{|c|c|c|c|}
\hline $\begin{array}{c}\text { Post-tensioning force } \\
(\mathrm{kN})\end{array}$ & $\begin{array}{c}\text { Ultimate load } \\
(\mathrm{kN})\end{array}$ & $\begin{array}{c}\text { Maximum contact pressure } \\
(\mathrm{MPa})\end{array}$ & $\begin{array}{c}\text { Horizontal thrust reduction } \\
\text { at abutments }(\%)\end{array}$ \\
\hline 1 & 6.00 & 3.20 & 3.11 \\
\hline 2 & 7.80 & 3.27 & 6.31 \\
\hline 3 & 9.60 & 3.33 & 9.43 \\
\hline 4 & 11.40 & 3.39 & 12.47 \\
\hline 5 & 13.20 & 3.45 & 15.50 \\
\hline 6 & 15.00 & 3.52 & 18.55 \\
\hline 7 & 16.70 & 3.51 & 21.61 \\
\hline 8 & 18.50 & 3.59 & 24.61 \\
\hline 9 & 20.30 & 3.66 & 27.57 \\
\hline 10 & 22.10 & 3.74 & 30.55 \\
\hline
\end{tabular}

A positive linear relationship was found between the post-tensioning force and both the ultimate load capacity of the arch ring and the reduction of the horizontal thrust at the abutments - i.e., as the post-tensioning force increases, so will increase the value of the ultimate load and the value for the horizontal thrust reduction at the abutments. From the results, the following can be concluded: 
- Post-tensioning loads reduced the displacement caused by self-weight, thus increasing the arch stability.

- A reduction of the horizontal thrust transferred to the abutments of the bridge was achieved.

- The 4 cables arrangement is the more effective of the studied arrangements.

- At none of the analysis with the different post-tensioning forces the maximum value of the pressure between vousoirs exceeded $10 \%$ of the compressive stress of the Granite.

\section{Comparison with other available strengthening techniques}

Several strengthening techniques are available nowadays and could be applied in masonry arch bridges. A selection of them was done after what was found in the literature and is presented in Table 3 . The factors under discussion on this report are not related to whether the technique is able to achieve an improvement on the structural response of the structure, all the techniques attain that goal at some extent according to the references. It focuses on whether the interventions are sympathetic and respect the criteria stablished in conservation charters for monuments and historical constructions (see [9]). A rough qualitative appreciation was done using three levels scale.

Table 3. Strengthening techniques comparison.

\begin{tabular}{|c|c|c|c|c|c|c|}
\hline Technique & $\begin{array}{c}\text { Minimum } \\
\text { intervention }\end{array}$ & Reversibility & $\begin{array}{c}\text { Compatibility } \\
\text { of materials }\end{array}$ & Durability & $\begin{array}{c}\text { Original } \\
\text { functionality }\end{array}$ & $\begin{array}{c}\text { Distinguisha- } \\
\text { bility }\end{array}$ \\
\hline $\begin{array}{c}\text { Grouting, repointing or sub- } \\
\text { stitution of damaged vousoirs } \\
\text { [6] }\end{array}$ & YES & YES & YES & MAYBE & YES & MAYBE \\
\hline $\begin{array}{c}\text { Insertion of steel RSJ's or RC } \\
\text { beams [1] }\end{array}$ & YES & YES & NO & MAYBE & YES & YES \\
\hline $\begin{array}{c}\text { Sprayed concrete to the intra- } \\
\text { dos [3] }\end{array}$ & NO & NO & NO & MAYBE & NO & YES \\
\hline Concrete saddles [3] & NO & NO & NO & YES & NO & YES \\
\hline Arch stitching [3], [6] & NO & NO & MAYBE & MAYBE & NO & YES \\
\hline Glued steel bars or wood [3] & NO & NO & MAYBE & MAYBE & NO & YES \\
\hline FRP, FRCM, TRM* [3], [6] & NO & NO & MAYBE & MAYBE & NO & YES \\
\hline Borri \& Castori [3] & MAYBE & NO & NO & MAYBE & YES & YES \\
\hline "RAM", [2] & MAYBE & NO & MAYBE & MAYBE & YES & YES \\
\hline This report's proposal & MAYBE & YES & MAYBE & MAYBE & YES & YES \\
\hline
\end{tabular}

*FRP = Fiber Reinforced Polymers, FRCM = Fiber Reinforced Cementitious Matrix, TRM = Textile reinforced mortar.

Some authors, (see [1] and [6]), even consider the possibility of not performing any intervention at all. Since sometimes adequate strengthening techniques may pose a high technical challenge and high costs, they suggest building a new bridge and close or limit the use of the existing damaged masonry arch bridge. This may not be a viable option neither since the best way to preserve historical constructions and monuments is to keep them in use. The construction of a new bridge will just increase the neglecting of the masonry arch bridge accelerating its decay and probably causing its total collapse.

\section{Conclusions}

By no means should this report be taken as an exhaustive or conclusive study of the strengthening technique proposed. Nevertheless, as a first approach and introductory study, it has revealed very promising results. 
The results obtained via simple non-linear FEM models based on the assumed hypothesis, show that the proposal effectively increases the ultimate load capacity of the arch ring. It was also shown that the post-tensioning arrangement can contain at certain level the horizontal thrust at the abutments. The proposed technique is deemed to be sympathetic and compatible with the intervention philosophy of the charters on conservation of monuments and historical constructions.

If the numerical simulations presented in this paper were successfully validated in an experimental campaign, this external post-tensioning arrangement would represent a viable intervention alternative for the repairing and strengthening of historical stone masonry arches.

\section{Acknowledgments}

The authors would like to acknowledge Trinity College Dublin and the Department of Civil, Structural and Environmental Engineering for the support that allowed the completion of this paper.

\section{References}

[1] O'Dwyer, D., Handouts from the Postgraduate Diploma in Applied Building Repair and Conservation. 2017, Trinity College Dublin, Department of Civil, Structural and Environmental Engineering: Dublin, Ireland.

[2] Jurina, L., Experimental tests on consolidation of masonry bridges using "RAM-Reinforced Arch Method". In 8th International Conference on Arch Bridges. 2016: Wroclaw, Poland.

[3] D'Ayala, D. and E. Fodde, eds. Structural analysis of historic construction: preserving safety and significance: Proceedings of the Sixth International Conference on Structural Analysis of Historic Construction, 2-4 July, Bath, United Kingdom. 2008, CRC Press: Boca Raton. 2 v. (xix, 1574 p.).

[4] Heyman, J., The masonry arch. Ellis Horwood series in engineering science. 1982, Chichester: Horwood. 117p.

[5] Construction Industry Research and Information Association., Great Britain. Department for Transport., and Network Rail (Firm), Masonry arch bridges: condition appraisal and remedial treatment. Ciria; C656. 2006, London: Ciria. $342 \mathrm{p}$.

[6] Theodossopoulos, D., Structural design in building conservation. 2012, London: Taylor \& Francis. xiv, 260 p.

[7] Heyman, J., The stone skeleton: structural engineering of masonry architecture. 1995, Cambridge: Cambridge University Press.

[8] ANSYS®, ANSYS® Academic Research Mechanical. 2017.

[9] ICOMOS, International Charters for Conservation and Restoration. Monuments and sites, ed. M. Petzet, Ziesemer, John; Vol. I. 2004, München. 